\title{
Are diabetes self-management programmes for the general diabetes population effective for people with severe mental illness?: a systematic review
}

\author{
Anne Coxon ${ }^{1}$, Hayley McBain ${ }^{1}$, Neli Pavlova ${ }^{1}$, Hannah Rowlands ${ }^{1}$ and Kathleen Mulligan ${ }^{1,2^{*}}$ (1)
}

\begin{abstract}
Background: Diabetes self-management education programmes are effective in improving health outcomes in the general population with diabetes. However, it is not known if these programmes include people who also have a severe mental illness (SMI) and, if so, what their outcomes are. The aim of this review was to examine if evaluations of diabetes self-management education programmes included people with SMI, and if so, whether the interventions were beneficial for this population.

Methods: The inclusion criteria for this systematic review, defined by PICOS criteria, were: Population - Adults with type 2 diabetes; Intervention - self-management education programme; Comparator - another active intervention or usual care; Outcomes of interest - inclusion of people with SMI and the clinical, behavioural and psychosocial outcomes in this population; Study design - randomised controlled trials.

The following bibliographic databases were searched from January 2004 to April 2018: Cochrane Library, Medline, Embase, PsychINFO, Allied and Complimentary Medicine Database, Health Technology Assessment, NHS Economic Evaluations Database and CINAHL. Data were extracted on study characteristics, inclusion and exclusion criteria, participant and intervention characteristics, number of participants with SMI, and outcomes for people with SMI, if reported. Authors were contacted by email for missing data.
\end{abstract}

Results: A total of 410 trials were included. At least $42 \%$ of trials did not recruit any participants with SMI. Only nine confirmed inclusion of participants with SMl, of which six provided data on the number recruited. These six trials recruited a total of 1009 participants, of whom 31 (3.1\%) had SMI. It was not possible to assess intervention effectiveness for people with SMI as none of the trials reported outcomes for these participants.

(Continued on next page)

\footnotetext{
* Correspondence: kathleen.mulligan.1@city.ac.uk

${ }^{1}$ Centre for Health Services Research, School of Health Sciences, City,

University of London, Northampton Square, London ECIV OHB, UK

${ }^{2}$ Community Health Newham, East London NHS Foundation Trust, Trust

Headquarters, 9 Alie Street, London E1 8DE, UK
}

(c) The Author(s). 2020 Open Access This article is licensed under a Creative Commons Attribution 4.0 International License, which permits use, sharing, adaptation, distribution and reproduction in any medium or format, as long as you give appropriate credit to the original author(s) and the source, provide a link to the Creative Commons licence, and indicate if changes were made. The images or other third party material in this article are included in the article's Creative Commons licence, unless indicated otherwise in a credit line to the material. If material is not included in the article's Creative Commons licence and your intended use is not permitted by statutory regulation or exceeds the permitted use, you will need to obtain permission directly from the copyright holder. To view a copy of this licence, visit http://creativecommons.org/licenses/by/4.0/ The Creative Commons Public Domain Dedication waiver (http://creativecommons.org/publicdomain/zero/1.0/) applies to the data made available in this article, unless otherwise stated in a credit line to the data. 
(Continued from previous page)

Conclusions: This systematic review confirms that people with SMI are often excluded from trials of diabetes selfmanagement education, resulting in a lack of an evidence base on which to base treatment paths for this vulnerable population. It cannot be assumed that programmes developed for the general diabetes population meet the needs of people with SMI. Future research needs to examine if and how these programmes could be adapted for people with SMI or if new programmes are required.

Keywords: Diabetes self-management education, DSME, Severe mental illness, SMI, Type 2 diabetes

\section{Background}

The estimated prevalence of diabetes mellitus in people with psychosis is $13 \%$, which is between two and five times higher than the general population [1]. Several factors are thought to contribute to this increased risk, including the effects of anti-psychotic medications, pathophysiology of SMI and lifestyle factors such as poor diet, obesity and physical inactivity [2]. Among people with diabetes mellitus, the risk of acute complications and mortality is also greater in those with SMI $[3,4]$.

Self-management of type 2 diabetes mellitus (T2DM) is complex, and to achieve this successfully, diabetes clinical guidelines [5-9] recommend structured education for all patients. A number of systematic reviews have reported the positive effects of diabetes self-management education (DSME) programmes [10-12], such as better glycaemic control, greater diabetes knowledge and selfmanagement skills, and higher self-efficacy, but it is unclear if people with SMI also experience these benefits. A recent Cochrane review of DSME specifically for people with SMI [12], conducted by members of the current authorship team, identified only one intervention [13], Diabetes Awareness and Rehabilitation Training (DART), which was evaluated in 64 people aged over 40 with T2DM and either schizophrenia or schizoaffective disorder. DART used adapted materials and reinforced behaviour change, to help overcome impaired motivation and insight. At the end of the 24-week trial, the DART group experienced a greater reduction in weight, body mass index (BMI), waist circumference and plasma triglycerides than controls, and had significantly increased their diabetes knowledge, diabetes self-efficacy and selfreported physical activity. The effects on participants' BMI, waist circumference and diabetes knowledge were maintained at 6-month follow-up [14]. There were however no statistically significant changes in fasting glucose or glycosylated haemoglobin $\left(\mathrm{HbA} 1_{\mathrm{C}}\right)$ levels. This study indicates that where interventions are developed to address the particular needs of people with SMI and T2DM, positive lifestyle changes can be achieved. The DART programme has since been combined with the Life Goals Program [15] (an intervention that focuses on mental health but not diabetes) to form the Targeted Training in Illness Management (TTIM) intervention, which has been tested in an RCT with 200 individuals with SMI and type 2 diabetes [16]. This 12-week group programme resulted in significantly better mental health and diabetes knowledge in the intervention group but no group differences were found in diabetes self-management behaviour or HbA1c.

Given that neither intervention [13, 16] achieved a change in $\mathrm{HbA}_{\mathrm{c}}$, this suggests a need for further research to identify how best to optimise diabetes selfmanagement for people with SMI to improve clinical as well as behavioural outcomes. The sparsity of evidence from SMI-specific DSME highlights that it is important to try to determine whether evidence of efficacy of DSME developed for the general diabetes population is also applicable to people with SMI. A rapid synthesis of the evidence on interventions supporting selfmanagement [17] identified 179 unique randomised controlled trials (RCTs) of DSME in the general diabetes population. This plethora of data may provide insight into whether and how DSME programmes for the general population have been implemented for people with SMI, and if they have been successful.

This systematic review therefore sought to answer the question: Are DSME programmes for the general diabetes population effective for people with SMI?

\section{Method}

Inclusion criteria, defined by Population, Intervention, Comparator, Outcome, and Study design (PICOS) [18] were:

Population - Adults aged 18 or over and diagnosed with T2DM.

Intervention - Interventions that were targeted to improve the self-management of T2DM by providing structured education. This could include interventions that targeted diabetes self-management behaviours such as self-monitoring of blood glucose, medication adherence, foot care, diet or physical activity. Although selfmanagement of SMI could be included, interventions that focused solely on the management of SMI without any diabetes education were excluded. Interventions could be delivered individually or in groups, in person or remotely e.g. telephone or online. 
Comparator - comparators were either another active intervention or usual care.

Outcomes - outcomes of interest were: inclusion of people with SMI (defined as psychosis, schizophrenia, schizoaffective disorder, bipolar disorder, depression with psychotic features or personality disorder); number (\%) of participants with SMI; plus clinical (HbA1c, body mass index, weight, blood pressure), behavioural (diabetes self-care behaviours such as blood glucose monitoring, medication adherence, diet and physical activity), and psychosocial (health-related quality of life, diabetes knowledge, self-efficacy) outcomes for participants with SMI.

Study design - RCTs

Publications were excluded if they:

- included only participants with type 1 diabetes or gestational diabetes

- were written in languages other than English

- were published as conference abstracts, editorials, or letters

- had not undergone formal peer review.

Trials that recruited only people with T2DM and SMI were also excluded as the recent Cochrane review [12] had already reviewed these.

\section{Search strategy}

A systematic literature search was undertaken in the following databases: Cochrane Library, Medline, Embase, PsychINFO, Allied and Complimentary Medicine Database, Health Technology Assessment, NHS Economic Evaluations Database and CINAHL from January 2004 to April 2018. The search included terms for diabetes, patient education/self-management and RCTs. The full list of terms is reported in Additional file 1.

\section{Study selection}

Retrieved articles were imported into Reference Manager bibliographic software version 12 and duplicates removed. Titles and abstracts were independently screened against inclusion criteria by two reviewers (two of AC, KM, HR, NP, RS). Full texts of the remaining articles were then obtained and independently screened for inclusion by two reviewers (two of AC, KM, HR, NP, RS). Any disagreements were discussed with a third reviewer (KM or HM).

Data were extracted by three of the review team (AC, NP, HR) using an adapted Cochrane data extraction form [19], which included information on study characteristics, inclusion and exclusion criteria, participant characteristics, intervention characteristics, number included with SMI, and outcomes for people with SMI, if reported. If the article did not report this information on SMI, authors were contacted by email for missing data.

Risk of bias in those trials that reported inclusion of people with SMI was independently assessed by two authors (KM and HM) using the Cochrane Collaboration tool [20]. Trials were rated as low, high or unclear risk of bias across seven criteria: sequence generation; allocation concealment; blinding of participants or personnel; blinding of outcome assessors; incomplete outcome data; selective reporting and other bias. Any disagreements were discussed to achieve consensus. Potential publication bias was assessed by creating a funnel plot of effect estimates against their standard errors for the outcome of Hbalc and conducting Egger's test for asymmetry of the funnel plot.

\section{Data analysis}

Descriptive statistics were used to calculate the proportion of trials that included participants with SMI. Where trials reported outcomes for participants with SMI, we planned to assess treatment effects using a randomeffects meta-analysis.

\section{Results}

From an initial 52,265 titles, 885 full texts were assessed for eligibility. A total of 410 RCTs, conducted in 53 different countries, were included in the review. (See PRIS MA flowchart shown in Fig. 1). Studies conducted in the USA dominated $(n=134,33 \%)$, followed by the UK (32, $8 \%)$, Iran $(23,5.6 \%)$ and China $(20,4.9 \%)$. Six trials (1.5\%) were multinational.

Results for recruitment of people with SMI are reported in Table 1 and Additional file 2. Of 410 included trials, $110(26.8 \%)$ listed SMI in the publication inclusion/exclusion criteria (of which 109 excluded SMI), we received information from authors on a further 123 (30\%) but authors of 177 (43.2\%) trials did not respond to our email requests for information.

Of the 410 trials, at least 172 (42\%) RCTs did not recruit any participants with SMI; this was $74 \%$ of the 233 trials on which we were able to obtain data. In 229 (55.9\%) RCTs, it is unknown if people with SMI were recruited, either because the authors did not respond to our request for information $(n=177,43.2 \%)$ or because the authors were unaware if they had recruited any participants with SMI as this data was not collected $(n=52$, $12.7 \%)$.

Nine (2.2\%) RCTs [21-29] confirmed inclusion of people with SMI following email requests; however, of these, only six $[21-23,25,28,29]$ provided data on the numbers recruited and none provided data on effectiveness of the interventions in their participants with SMI. The six trials that provided data recruited a total of 1009 participants with T2DM, of whom 31 (3.1\%) had SMI. 


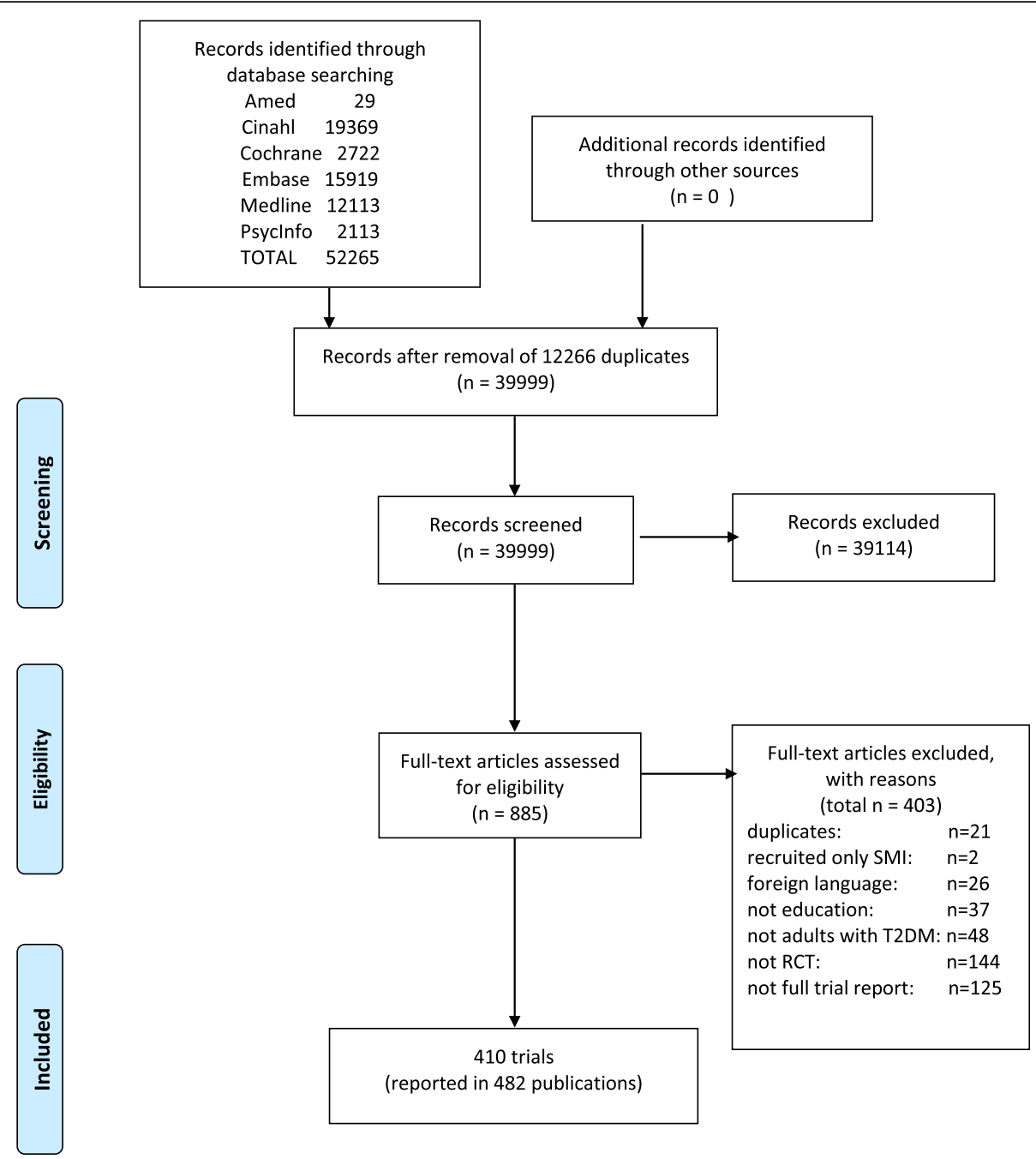

Fig. 1 PRISMA flow diagram

Table 1 Number and \% of RCTs that included or excluded participants with SMI

\begin{tabular}{|c|c|c|c|c|}
\hline & \multirow[b]{2}{*}{$\mathrm{N}$} & \multirow[b]{2}{*}{$\%$} & \multicolumn{2}{|c|}{ TOTALS } \\
\hline & & & $n$ & $\%$ \\
\hline Included SMI & & & 9 & 2.2 \\
\hline Authors provided data on numbers recruited but not effectiveness & 6 & 1.5 & & \\
\hline Authors did not provide data on numbers recruited or effectiveness & 3 & 0.7 & & \\
\hline Did not include SMI & & & 172 & 42.0 \\
\hline \multicolumn{5}{|l|}{ Explicitly excluded SMI: } \\
\hline Reported in paper & 109 & 26.6 & & \\
\hline Response from authors & 47 & 11.5 & & \\
\hline Not explicitly excluded but no-one with SMI recruited & 16 & 3.9 & & \\
\hline Unknown if SMI included & & & 229 & 55.9 \\
\hline Authors did not collect data on SMI & 52 & 12.7 & & \\
\hline Authors did not respond to email request & 177 & 43.2 & & \\
\hline TOTAL RCTS & 410 & & 410 & \\
\hline
\end{tabular}


This is in line with population prevalence, in which approximately $2 \%$ of people with type 2 diabetes have SMI (approximately double that of the general population) $[29,30]$.

The six trials that provided data on participants with SMI were conducted in Brazil [23], New Zealand [28], Qatar [22], Slovenia [29] and the United States [21, 25]. The interventions they evaluated were varied. Mohamed et al. [22] trialled a culturally sensitive group intervention including education on diabetes, healthy eating and exercise, and included five participants with schizophrenia. An individual programme trialled in Brazil [23] evaluated education plus blood glucose monitoring and pharmacotherapy adjustment. This trial included one participant with bipolar disorder, two with depression with psychotic features, and one participant diagnosed with personality disorder. The DECIDE education and problem-solving training programme was evaluated in two trials with African-American populations [21, 25]. The first [21] compared intensive and condensed versions and included one participant with schizophrenia, two with bipolar disorder and one participant with other psychosis. The second [25] compared self-study, individual and group versions of DECIDE and recruited eight people with SMI, six with schizophrenia, one with bipolar disorder and one who had depression with psychotic features. Whitehead et al. 2017 [28] recruited one person with SMI (personality disorder) to their comparison of nurse-led education plus Acceptance and Commitment Therapy (ACT) with nurse-led education alone or usual care. Two different levels of intensity of multidisciplinary care plus education were compared in a trial [23] that recruited four participants with SMI - one with bipolar disorder, two who had depression with psychotic features and one with personality disorder. The final trial [29], which recruited six people with SMI (one with schizophrenia, one with schizoaffective disorder, three with bipolar disorder and one who had depression with psychotic features) evaluated telemedicine plus education compared with usual care. None of these interventions incorporated components that specifically targeted issues around managing SMI.

Assessment of Risk of Bias for the nine trials that included people with SMI is shown in Fig. 2. Risk of bias was mostly unclear for random sequence generation, allocation concealment and blinding of outcome assessment. All trials were rated high risk of bias for blinding of participants and personnel, which is unavoidable given the type of intervention. Risk of bias for incomplete outcomes data was rated as high in four trials, mostly because of differential dropout between trial arms. Selective reporting was rated as high or unclear risk of bias in most studies where they had not reported registration of the trial protocol and/or had not reported

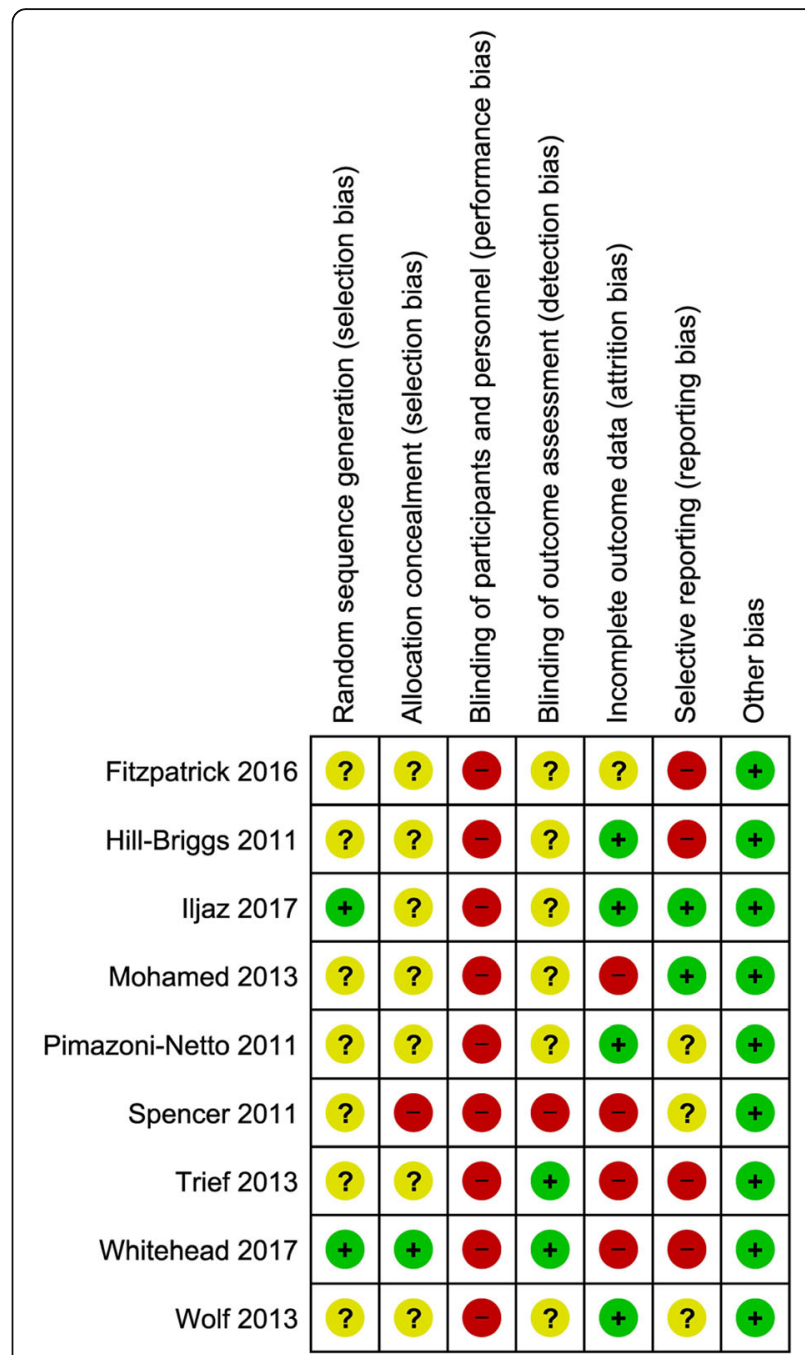

Fig. 2 Risk of bias summary for trials that included participants with severe mental illness

data in sufficient detail to enter into a meta-analysis/funnel plot. Only five trials reported sufficient data for the funnel plot, which is shown in Fig. 3. The result of the Egger's test for asymmetry of the funnel plot was nonsignificant ( $\beta$ 0.54, SE 0.17 (95\% CI 0.08-1.01), $p=0.47$ ), which suggests a low risk of publication bias, however this finding should be interpreted with caution in view of the small number of included trials.

The trials did not report, or were unable to provide, the results for participants with SMI; we therefore did not conduct analysis of treatment effects in people with SMI for these trials.

\section{Discussion}

The key findings of this review reveal that at least $42 \%$ of identified trials of DSME do not include any participants with SMI and only $2 \%$ had participants with a known diagnosis of SMI. 


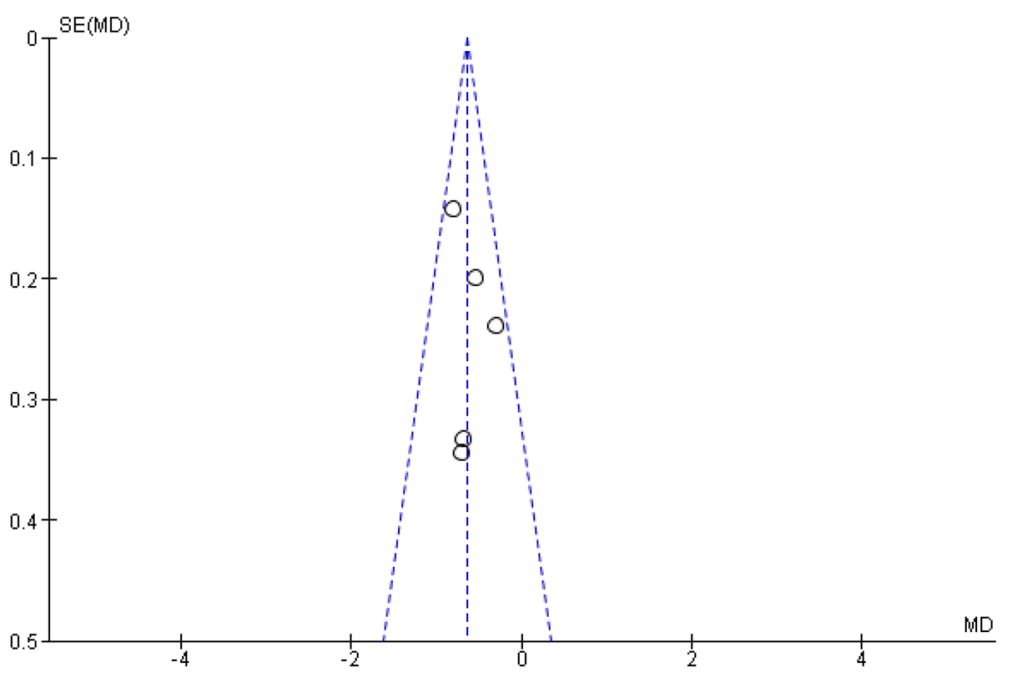

Fig. 3 Funnel plot of estimates of effect on $\mathrm{HbA} 1 \mathrm{c}$

None of the interventions tested in these trials incorporated components that specifically targeted mental health issues that may affect self-management of diabetes and none of the trials reported data on effectiveness of the interventions for people with SMI.

Given the increased risk of T2DM in people with SMI and the large number of RCTs of DSME that have been conducted, their omission from trials of DSME is remarkable. However, our findings echo previous research [31], which has also found that people with SMI are often excluded from clinical trials. Of 400 highly cited trials across 20 common chronic health conditions published between 2002 and 2010, 55\% of the papers that described diabetes research had psychiatric exclusion criteria [31]. Humphreys et al. argued that excluding this population results in knowledge gaps that may harm people with SMI when a treatment becomes generalised [31].

The recent Cochrane review [12] identified only one intervention [13] that had been developed and evaluated for people with T2D and SMI, which has since been adapted and evaluated in another trial [16]. The small number of trials in the current review that included people with SMI did not specifically address the particular challenges faced by this population, for example, how to maintain diabetes control during periods of instability in their mental health $[32,33]$. Furthermore, as the numbers recruited were small, which is not unexpected given the population prevalence of SMI, it is not possible to tell if these interventions were beneficial for people with SMI. These findings together indicate that the provision of evidence-based diabetes education is lacking for people with SMI.

The King's Fund [34] has recommended that people with SMI should be seen as a priority target group for public health interventions and the UK National Health
Service (NHS) Long Term Plan [35] stresses the need for people with SMI to have their physical health needs met. However, our findings concur with other research that has identified under-representation of people with psychiatric disorders in diabetes research and highlighted this issue as an example of health inequity [31]. It is unclear to what extent this underrepresentation in research on DSME is also borne out in referral to these programmes in clinical care. Research in the US has found that people with SMI are less likely than those without SMI to receive diabetes education [36] but this may not be the case in the UK [33].

Thornicroft [37] has described the mortality gap between people with SMI and the non-SMI population as "at worst a form of lethal discrimination" and calls for evidence-based interventions to address it. Furthermore, the Royal College of Psychiatrists [38] has recommended that their members should feel competent to address the physical as well as the mental health needs of people with SMI. Similarly, psychiatric associations internationally [39-41] consider the role of psychiatrists to include improving the physical as well as mental health of their patients. However, the lack of research into the effectiveness of DSME programmes in this vulnerable group leaves clinicians without a clear pathway for intervention.

If people with SMI are to be referred to general DSME programmes, it is essential that the programmes are evaluated in this population. Given the population prevalence of SMI in people with diabetes, recruitment of sufficient people with SMI to achieve adequate statistical power would require trials that oversample people with SMI when recruiting. However, in other research $[32,33]$ we have identified that learning how to maintain diabetes control during periods of instability in mental health would be an important aspect of DSME for 
people with SMI. As generic DSME programmes do not address this crucial issue, they will need to be adapted, or more tailored interventions developed and evaluated, if DSME is to meet the needs of people with SMI.

A limitation of this review is that, in spite of our attempts to contact all authors, we were unable to obtain data for a substantial number of trials. It is possible, therefore, that our findings could under- or overestimate the proportion of trials that do not include SMI. We received responses from authors of 124 RCTs that had not reported data in the trial publication, and of these, 63 (51\%) did not have any participants with SMI. If this pattern was repeated for the trials on which we were unable to obtain data, it would raise the proportion who have not included SMI above the $42 \%$ reported.

We also acknowledge that we may not have identified all relevant trials, for example, we did not search grey literature or include papers published in languages other than English.

\section{Conclusion}

Very few tailored DSME programmes exist for people with T2DM and SMI therefore people with these conditions may be referred to generic DSME programmes. This systematic review has shown that trials of generic DSME programmes often exclude people with SMI and where they do include people with SMI, efficacy in this population is not tested. We therefore do not know if the DSME programmes to which people with T2DM are referred are effective for people with SMI. If people with SMI are to receive appropriate diabetes care in accordance with current guidelines, it is essential that evidence-based diabetes education is available. It is necessary for future research to examine whether existing programmes can meet the needs of people with SMI, or be adapted to do so, or if more tailored programmes need to be developed and evaluated.

\section{Supplementary information}

Supplementary information accompanies this paper at https://doi.org/10. 1186/s12888-020-02779-7.

Additional file 1. Search terms.

Additional file 2. Study Characteristics.

\section{Abbreviations}

$\mathrm{A} 1_{c}$ or $\mathrm{HbA} 1_{c}$ : Glycosylated haemoglobin; BMI: Body mass index; DSME: Diabetes self-management education; SMI: Severe mental illness; T2DM: Type 2 diabetes mellitus

\section{Acknowledgements}

Anne Coxon's contribution to this work was conducted in part fulfilment of the requirements of a Professional Doctorate in Health Psychology [42]. Reesha Solanki, reesha96@hotmail.co.uk, helped with conducting the literature searches and screening of study titles for inclusion in the review.

\section{Authors' contributions}

$\mathrm{KM}$ and $\mathrm{HM}$ were involved in the conception and design of the study. AC, $\mathrm{NP}, \mathrm{HR}$ and $\mathrm{KM}$ were involved in study selection and data extraction. AC and KM completed data analysis. KM, HM and AC were involved in data interpretation, either drafting or revising the intellectual content of the manuscript and approving the final version for publication. RS did not meet the journal criteria for authorship but is named in the acknowledgements for assisting with literature searches and title screening. All authors have read and approved the manuscript.

\section{Funding}

This research was unfunded.

Availability of data and materials

Data are available on request from the corresponding author.

Ethics approval and consent to participate

As this is a systematic review of published data, ethical approval or consent to participate were not required.

Consent for publication

Not applicable.

\section{Competing interests}

The authors declare that they have no competing interests.

Received: 4 September 2019 Accepted: 5 July 2020

Published online: 25 July 2020

\section{References}

1. Ward M, Druss B. The epidemiology of diabetes in psychotic disorders. Lancet Psychiatry. 2015;2(5):431-51.

2. Osborn DP, Wright CA, Levy G, King MB, Deo R, Nazareth I. Relative risk of diabetes, dyslipidaemia, hypertension and the metabolic syndrome in people with severe mental illnesses: systematic review and meta-analysis. BMC Psychiatry. 2008:8:84.

3. Becker T, Hux J. Risk of acute complications of diabetes among people with schizophrenia in Ontario, Canada. Diabetes Care. 2011;34(2):398-402.

4. Vinogradova Y, Coupland C, Hippisley-Cox J, Whyte S, Penny C. Effects of severe mental illness on survival of people with diabetes. Br J Psychiatry. 2010;197(4):272-7.

5. National Institute for Health and Care Excellence, Type 2 diabetes in adults: management. 2015. nice.org.uk/guidance/ng28.

6. Powers MA, Bardsley J, Cypress M, Duker P, Funnell MM, Hess FA, et al. Diabetes self-management education and support in type 2 diabetes: a joint position statement of the American Diabetes Association, the American Association of Diabetes Educators, and the academy of nutrition and dietetics. Diabetes Care. 2015;38(7):1372-82.

7. Scottish Intercollegiate Guidelines Network, SIGN 116: Management of Diabetes. 2010. www.sign.ac.uk/assets/sign116.pdf.

8. International Diabetes Federation, Global Guidelines for Type 2 Diabetes. 2012. https://www.iapb.org/wp-content/uploads/Global-Guideline-forType-2-Diabetes-IDF-2012.pdf.

9. Royal Australian College of General Practitioners, General practice management of type 2 diabetes 2016-18. 2016. https://www.racgp.org.au/ FSDEDEV/media/documents/Clinical\%20Resources/Guidelines/Diabetes/ General-practice-management-of-type-2-diabetes_1.pdf.

10. Chrvala CA, Sherr D, Lipman RD. Diabetes self-management education for adults with type 2 diabetes mellitus: a systematic review of the effect on glycemic control. Patient Educ Couns. 2016;99(6):926-43.

11. Steinsbekk A, Rygg L, Lisulo M, Rise MB, Fretheim A. Group based diabetes self-management education compared to routine treatment for people with type 2 diabetes mellitus. A systematic review with meta-analysis. BMC Health Serv Res. 2012;12:213.

12. McBain H, Mulligan K, Haddad M, Flood C, Jones J, Simpson A. Self management interventions for type 2 diabetes in adult people with severe mental illness. Cochrane Database Syst Rev. 2016:4:CD011361.

13. McKibbin $\mathrm{CL}$, Patterson TL, Norman G, Patrick K, Jin H, Roesch S, et al. A lifestyle intervention for older schizophrenia patients with diabetes mellitus: a randomized controlled trial. Schizophr Res. 2006;86(1-3):36-44. 
14. McKibbin CL, Golshan S, Griver K, Kitchen K, Wykes TL. A healthy lifestyle intervention for middle-aged and older schizophrenia patients with diabetes mellitus: a 6-month follow-up analysis. Schizophr Res. 2010;121(13):203-6.

15. Bauer MS, McBride L. Structured group psychotherapy for bipolar disorder: the life goals program. New York: Springer; 2003.

16. Sajatovic M, Gunzler DD, Kanuch SW, Cassidy KA, Tatsuoka C, McCormick R, et al. A 60-week prospective RCT of a self-management intervention for individuals with serious mental illness and diabetes mellitus. Psychiatr Serv. 2017:68(9):883-90.

17. Taylor SJC, Pinnock H, Epiphaniou E, Pearce G, Parke HL, Schwappach A, et al. A rapid synthesis of the evidence on interventions supporting selfmanagement for people with long-term conditions: PRISMS - Practical systematic Review of Self-Management Support for long-term conditions. Southampton: NIHR Journals Library; 2014.

18. Moher D, Liberati A, Tetzlaff J, Altman DG. Preferred reporting items for systematic reviews and meta-analyses: the PRISMA statement. Ann Intern Med. 2009;151(4):264-9.

19. Higgins JPT, Green S. Cochrane Handbook for Systematic Reviews of Interventions. Version 5.1.0. Chichester: Wiley-Blackwell; 2011.

20. Higgins JPT, Altman DG, Gøtzsche PC, Jüni P, Moher D, Oxman AD. The Cochrane Collaboration's tool for assessing risk of bias in randomised trials. BMJ. 2011;343:d5928.

21. Hill-Briggs F, Lazo M, Peyrot M, Doswell A, Chang YT, Hill MN, et al. Effect of problem-solving-based diabetes self-management training on diabetes control in a low income patient sample. J Gen Intern Med. 2011;26(9):972-8.

22. Mohamed $\mathrm{H}$, Al-Lenjawi B, Amuna $\mathrm{P}$, Zotor $\mathrm{F}$, Elmahdi $\mathrm{H}$. Culturally sensitive patient-centred educational programme for self-management of type 2 diabetes: a randomized controlled trial. Prim Care Diabetes. 2013;7(3):199206.

23. Pimazoni-Netto A, Rodbard D, Zanella MT. Rapid improvement of glycemic control in type 2 diabetes using weekly intensive multifactorial interventions: structured glucose monitoring, patient education, and adjustment of therapy-a randomized controlled trial. Diabetes Technol Ther. 2011;13(10):997-1004.

24. Wolf MS, Seligman H, Davis TC, Fleming DA, Curtis LM, Pandit AU, et al. Clinic-based versus outsourced implementation of a diabetes health literacy intervention. J Gen Intern Med. 2013;29(1):59-67.

25. Fitzpatrick SL, Golden SH, Stewart K, Sutherland J, DeGross S, Brown T, et al. Effect of DECIDE (decision-making education for choices in diabetes everyday) program delivery modalities on clinical and behavioral outcomes in urban African Americans with type 2 diabetes: a randomized trial. Diabetes Care. 2016;39(12):2149-57.

26. Spencer MS, Rosland AM, Kieffer EC, Sinco BR, Valerio M, Palmisano G, et al. Effectiveness of a community health worker intervention among African American and Latino adults with type 2 diabetes: a randomized controlled trial. Am J Public Health. 2011;101(12):2253-60.

27. Trief PM, Izquierdo R, Eimicke JP, Teresi JA, Goland R, Palmas W, et al. Adherence to diabetes self care for white, African-American and Hispanic American telemedicine participants: 5 year results from the IDEATel project. Ethn Health. 2013;18(1):83-96.

28. Whitehead LC, Crowe MT, Carter JD, Maskill VR, Carlyle D, Bugge C, et al. A nurse-led education and cognitive behaviour therapy-based intervention among adults with uncontrolled type 2 diabetes: a randomised controlled trial. J Eval Clin Pract. 2017;23(4):821-9.

29. Iljaz R, Brodnik A, Zrimec T, Cukjati I. E-healthcare for diabetes mellitus type 2 patients - a randomised controlled trial in Slovenia. Zdr Varst. 2017;56(3): 150-7.

30. NHS Digital, National Diabetes Audit, 2016-17 report 1: care processes and treatment targets. Severe Mental IIIness - Supplementary Information. 2018. www.hqip.org.uk/wp-content/uploads/2018/03/National-Diabetes-Audit-2 016-17-Report-1-SMI-Care-Processes-and-Treatme....pdf. Accessed 1 Aug 2019.

31. Humphreys K, Blodgett JC, Roberts LW. The exclusion of people with psychiatric disorders from medical research. J Psychiatr Res. 2015;70:28-32.

32. Mulligan K, McBain H, Lamontagne-Godwin F, Chapman J, Haddad M, Jones $J$, et al. Barriers and enablers of type 2 diabetes self-management in people with severe mental illness. Health Expect. 2017;20(5):1020-30.

33. Mulligan K, McBain H, Lamontagne-Godwin F, Chapman J, Flood C, Haddad $M$, et al. Barriers to effective diabetes management - a survey of people with severe mental illness. BMC Psychiatry. 2018;18(1):165.
34. Naylor CDP, Ross S, Honeyman M, Thompson J, Gilburt H. Bringing together physical and mental health. A new frontier for integrated care. London: The King's Fund; 2016.

35. National Health Service, The NHS long term plan. 2019. www.longtermplan. nhs.uk/wp-content/uploads/2019/01/nhs-long-term-plan-june-2019.pdf.

36. Goldberg RW, Kreyenbuhl JA, Medoff DR, Dickerson FB, Wohlheiter K, Fang LJ, et al. Quality of diabetes care among adults with serious mental illness. Psychiatr Serv. 2007;58(4):536-43.

37. Thornicroft G. Premature death among people with mental illness. BMJ. 2013;346:f2969.

38. Royal College of Psychiatrists, Physical health in mental health. Final report of a scoping group. 2009. https://www.ucl.ac.uk/core-study/sites/core-study/ files/18physical_mental.pdf.

39. De Hert M, Dekker JM, Wood D, Kahl KG, Holt RIG, Möller HJ. Cardiovascular disease and diabetes in people with severe mental illness position statement from the European Psychiatric Association (EPA), supported by the European Association for the Study of Diabetes (EASD) and the European Society of Cardiology (ESC). Eur Psychiatry. 2009;24(6):412-24.

40. De Hert M, Correll CU, Bobes J, Cetkovich-Bakmas M, Cohen D, Asai I, et al. Physical illness in patients with severe mental disorders. I. Prevalence, impact of medications and disparities in health care. World Psychiatry. 2011; 10(1):52-77.

41. Royal Australian and New Zealand College of Psychiatrists, Keeping Body and Mind together: Improving the physical health and life expectancy of people with serious mental illness. 2015. www.ranzcp.org/Files/Publications/ RANZCP-Keeping-body-and-mind-together.aspx.

42. Coxon A. Applying health psychology theory to practice: informing and developing interventions for long-term conditions. Thesis submitted in fulfilment of the requirements of the Professional Doctorate in Health Psychology. School of Health Sciences, City, University of London. 2018. https://openaccess.city.ac.uk/id/eprint/21605/1/Coxon,\%20Anne_Redacted. pdf.

\section{Publisher's Note}

Springer Nature remains neutral with regard to jurisdictional claims in published maps and institutional affiliations.

Ready to submit your research? Choose BMC and benefit from:

- fast, convenient online submission

- thorough peer review by experienced researchers in your field

- rapid publication on acceptance

- support for research data, including large and complex data types

- gold Open Access which fosters wider collaboration and increased citations

- maximum visibility for your research: over $100 \mathrm{M}$ website views per year

At $\mathrm{BMC}$, research is always in progress.

Learn more biomedcentral.com/submissions 